\title{
Laser Microdissection of Pisum sativum L. Nodules Followed by RNA-Seq Analysis Revealed Crucial Transcriptomic Changes during Infected Cell Differentiation
}

\author{
Pyotr G. Kusakin ${ }^{1}$ (D), Tatiana A. Serova ${ }^{1}$ (D), Natalia E. Gogoleva ${ }^{2,3}$, Yuri V. Gogolev 2,3 (D) \\ and Viktor E. Tsyganov $1,4, *$ (D) \\ 1 All-Russia Research Institute for Agricultural Microbiology, 196608 Saint Petersburg, Russia; \\ kussakin@gmail.com (P.G.K.); t_serova@rambler.ru (T.A.S.) \\ 2 Kazan Institute of Biochemistry and Biophysics, Kazan Scientific Center of RAS, 420111 Kazan, Russia; \\ negogoleva@gmail.com (N.E.G.); gogolev.yuri@gmail.com (Y.V.G.) \\ 3 Institute of Fundamental Medicine and Biology, Kazan Federal University, 420008 Kazan, Russia \\ 4 Saint-Petersburg Scientific Center RAS, 199034 Saint Petersburg, Russia \\ * Correspondence: vetsyganov@arriam.ru
}

\section{check for} updates

Citation: Kusakin, P.G.; Serova, T.A.; Gogoleva, N.E.; Gogolev, Y.V.;

Tsyganov, V.E. Laser Microdissection of Pisum sativum L. Nodules Followed by RNA-Seq Analysis Revealed Crucial Transcriptomic Changes during Infected Cell Differentiation.

Agronomy 2021, 11, 2504.

https://doi.org/10.3390/

agronomy11122504

Academic Editor: Petr Smýkal

Received: 30 October 2021

Accepted: 7 December 2021

Published: 9 December 2021

Publisher's Note: MDPI stays neutral with regard to jurisdictional claims in published maps and institutional affiliations.

Copyright: (c) 2021 by the authors. Licensee MDPI, Basel, Switzerland. This article is an open access article distributed under the terms and conditions of the Creative Commons Attribution (CC BY) license (https:/ / creativecommons.org/licenses/by/ $4.0 /)$.

\begin{abstract}
Garden pea (Pisum sativum L.) is a globally important legume crop. Like other legumes, it forms beneficial symbiotic interactions with the soil bacteria rhizobia, gaining the ability to fix atmospheric nitrogen. In pea nodules, the meristem is long-lasting and results in the formation of several histological zones that implicate a notable differentiation of infected host cells. However, the fine transcriptional changes that accompany differentiation are still unknown. In this study, using laser microdissection followed by RNA-seq analysis, we performed transcriptomic profiling in the early infection zone, late infection zone, and nitrogen fixation zone of 11-day-old nodules of pea wild-type line SGE. As a result, a list of functional groups of differentially expressed genes (DEGs) in different nodule histological zones and a list of genes with the most prominent expression changes during nodule development were obtained. Their analyses demonstrated that the highest amount of DEGs was associated with the nitrogen fixation zone. Among well-known genes controlling nodule development, we revealed genes that can be novel players throughout nodule formation. The characterized genes in pea were compared with those previously described in other legumes and their possible functions in nodule development are discussed.
\end{abstract}

Keywords: symbiosis; nodulation; infection zone; nitrogen fixation zone; transcriptomic analysis; garden pea

\section{Introduction}

Legumes play an important role in agrocenoses owing to their unique ability to enrich the soil with nitrogen. They are able to form a new organ, a nitrogen-fixing nodule, as a result of interaction with the soil bacteria rhizobia. In this organ, a low oxygen concentration is maintained, which is required for nitrogenase activity, the main enzyme of nitrogen fixation. The development of nodules includes partner recognition, signaling dialogue between symbionts, and bacterial and plant cell differentiation. The perception of plant flavonoids by rhizobia leads to transcriptional activation of their nodulation (nod) genes, resulting in the production of specific lipo-chitooligosaccharide signaling molecules (Nod factors) [1]. Nod factors induce specific responses in roots involving rearrangements of the root hair cytoskeleton [2] and the formation of infection threads, tubular structures extending into underlying cells and through which bacteria colonize plant cells [3]. Simultaneously, activation of divisions of the root cortex cells leads to formation of a nodule primordium. Via the infection threads, bacteria infect primordium cells that later form the nodule. 
In indeterminate nodules with a long-lasting apical meristem, several distinct histological zones are formed [4]. Beneath the meristem, cells start to differentiate, and they are penetrated by the net of infection threads from which rhizobia are released via infection droplets [5]. In infected cells, bacteria differentiate into bacteroids, which, being surrounded by the plant-derived symbiosome membranes, form organelle-like symbiosomes [6]. These cells form an infection zone that can be subdivided depending on the degree of cell differentiation into early (distal) and late (proximal) parts. The underlying nitrogen fixation zone comprises a significant part of the mature nodule and consists of enlarged infected cells filled with numerous nitrogen-fixing symbiosomes and a relatively small number of uninfected cells. With age, a senescence zone forms at the base of the nodule [4]. Significant metabolic changes occur in nodule cells during the transition to senescence: a decrease in nitrogenase activity, degradation of symbiosomes and bacteroids, and a decrease in the amount of leghemoglobin [7].

After bacterial release, the infected cells in indeterminate nodules undergo morphological changes and endoreduplication [8]. The process of differentiation of bacteria into bacteroids is under strict genetic control by the plant, as studies of numerous mutants of various legume species have shown $[9,10]$. Differentiation of infected cells primarily leads to an increase in their size. Unlike root cells, which grow anisotropically, infected cells in indeterminate nodules demonstrate isodiametric growth [11,12]. This type of growth produces an increase in the volume of an infected cell up to 80-fold greater than meristematic cells, and allows accommodation of tens of thousands of bacteroids [13].

It is obvious that understanding the molecular mechanisms of plant cell differentiation will serve as a fundamental basis for the breeding of highly efficient legume varieties that are able to use atmospheric nitrogen most efficiently. Currently, such mechanisms are being studied using model legumes. However, research using crop legumes is of particular interest because it will allow faster use of the obtained achievements directly in breeding. Garden pea (Pisum sativum) is a globally important legume crop [14]. Study of an abundant collection of pea symbiotic mutants [15] revealed that the process of differentiation of infected cells is strictly controlled by the host plant. Using P. sativum mutants impaired at the different stages of nodule development, it has been shown that the differentiation involves microtubular rearrangements during bacterial release and symbiosome hosting [11], gibberellin and cytokinin regulation [16,17], and plant-microbe interface remodeling [18-21]. Nevertheless, there is currently no information regarding the transcriptional regulation of the differentiation process in different zones of the pea nodule. Laser capture microdissection (LCM) enables the isolation of tissue regions and groups of cells from fixated specimens, allowing detailed research of transcriptional regulation of nodule development at different stages. There are several studies of the Medicago truncatula nodule transcriptome using this technique [22,23]. Recently, a new gene expression atlas combining a wide-range set of RNAseq data in M. truncatula was released [24]. Unfortunately, only one example of a gene expression atlas with coverage of DEGs in nodules without determination of tissue-specific expression is available for P. sativum [25]. To explore differences at the various stages of pea nodule development, we compared the transcriptomic profiles of infected cells from the early infection zone (e-II zone), late infection zone (1-II zone), and nitrogen fixation zone (III zone) of wild-type pea nodules at 11 days after inoculation. Samples of each cell type were isolated using LCM followed by RNA-seq. As a result, we established a list of functional groups of differentially expressed genes (DEGs) in different nodule histological zones and here discuss the possible involvement of genes with the most prominent expression changes in nodule development.

\section{Materials and Methods}

\subsection{Plant Material, Inoculation, and Growth Conditions}

Seeds of P. sativum L. wild-type line SGE [26] were surface-sterilized in concentrated sulfuric acid for $30 \mathrm{~min}$ and washed with sterile water 10 times. Then, seeds were transferred to Petri dishes with sterile vermiculite and germinated in the dark for 2 days at $25^{\circ} \mathrm{C}$. 
The seedlings were transferred into sterile vermiculite with nutrition solution without nitrogen [27] and inoculated with Rhizobium leguminosarum bv. viciae 3841 strain [28]. The plants were grown in an MLR-352H growth chamber (Sanyo Electric Co., Moriguchi, Japan) under a $16 \mathrm{~h}$ light $/ 8 \mathrm{~h}$ dark cycle, at $21^{\circ} \mathrm{C}$ and $75 \%$ humidity, photosynthetic photon flux density of $\sim 280 \mu \mathrm{mol}$ photons $\mathrm{m}^{-2} \mathrm{~s}^{-1}$ (Panasonic FL40SS-ENW/37 lamps, Panasonic Malaysia Sdn. Bhd., Petaling Jaya, Malaysia).

\subsection{Laser Microdissection}

Samples were prepared for laser microdissection and pressure catapulting (LMPC) as described previously [29]. For this analysis, 11-day-old nodules were used. Laser microdissection was conducted with a PALM MicroBeam System (Zeiss, Oberkochen, Germany). Sections were visualized on a computer monitor using an Axiocam ICc 1 video camera (Zeiss). The samples, selected with PALM RoboSoftware 4.3 (Zeiss) and isolated using an ultraviolet laser (350 nm), are listed in Table 1. Selected cells were catapulted into the Adhesive Cap (Zeiss) and lysed using the extraction buffer included in the PicoPure ${ }^{\mathrm{TM}}$ RNA Isolation Kit (Arcturus Engineering Inc., Mountain View, CA, USA) in accordance with the manufacturer's instructions.

Table 1. The amount of material obtained after laser microdissection of the early and late infection zones (II), as well as infected cells of the nitrogen fixation zone (III).

\begin{tabular}{ccccc}
\hline Replicate & Nodules & $\begin{array}{c}\text { Nodule } \\
\text { Zone }\end{array}$ & $\begin{array}{c}\text { Number of } \\
\text { Sections }\end{array}$ & $\begin{array}{c}\text { Number of } \\
\text { Areas Cut }\end{array}$ \\
\hline \multirow{2}{*}{1} & \multirow{2}{*}{40} & Early II & & 594 \\
& Late II & 594 & 594 \\
& III & & 6799 \\
\hline \multirow{2}{*}{3} & \multirow{2}{*}{38} & Early II & \multirow{2}{*}{662} & 662 \\
& Late II & & 662 \\
& \multirow{2}{*}{46} & III & \multirow{2}{*}{616} & 616 \\
& Early II & & 616 \\
& Late II & III & & 5984 \\
\hline
\end{tabular}

${ }^{1}$ In the early and late infection zones, the number of excised areas corresponds to the number of sections owing to the difficulty of identifying individual cells in these areas on slides. Each excised area from the nitrogen fixation zone contained 1-3 infected cells.

\subsection{RNA Extraction}

Total RNA was extracted from samples using a PicoPure RNA Isolation Kit in accordance with the manufacturer's instructions (70\% ethanol was added to the lysate instead of $90 \%$ ). Elution of total RNA was performed twice with $11 \mu \mathrm{L}$ of elution buffer. The concentration of the extracted RNA was measured using Qubit 2.0 (Invitrogen, Carlsbad, CA, USA). Extracted total RNA was precipitated with $2 \mu \mathrm{L}$ of GlycoBlue ${ }^{\mathrm{TM}}$ Coprecipitant (15 $\mu \mathrm{g} / \mu \mathrm{L}$; Invitrogen), $1 / 10 \mathrm{~V}$ of $3 \mathrm{M}$ sodium acetate, $\mathrm{pH} 5.5$ (Invitrogen), and $3 \mathrm{~V}$ of $96 \%$ ethanol.

\subsection{Depletion of Ribosomal RNA and RNA Amplification}

A RiboMinus ${ }^{\mathrm{TM}}$ Plant Kit for RNA-Seq (Invitrogen) was used for the removal of plant ribosomal RNA (rRNA) from total RNA in accordance with the manufacturer's manual. Then, the rRNA-free RNA fraction was concentrated by precipitation with $2 \mu \mathrm{L}$ of GlycoBlue $^{\mathrm{TM}}$ Coprecipitant $(15 \mu \mathrm{g} / \mu \mathrm{L}$; Invitrogen), $1 / 10 \mathrm{~V}$ of $3 \mathrm{M}$ sodium acetate, $\mathrm{pH} 5.5$ (Invitrogen), and $3 \mathrm{~V}$ of $96 \%$ ethanol. RNA precipitate was washed with $70 \%$ ethanol and resuspended with $40 \mu \mathrm{L}$ of RNAse free water. Residual oligonucleotides were removed with DNAse I (Zymo Research, Irvine, CA, USA) and RNA was purified using a Clean \& Concentrator ${ }^{\mathrm{TM}}$ kit (Zymo Research) in accordance with the manufacturer's instructions. The RNA concentration was measured with Qubit 2.0. To obtain a sufficient amount of mRNA for transcriptome analysis and real-time PCR, a single round of RNA amplification was performed with a MessageAmp II Bacteria kit (Invitrogen). Only plant mRNA was 
amplified because the polyadenylation step was omitted. The cDNA templates were then removed using DNAse I (Zymo Research) and amplified RNA purification was carried out with a SurePrep RNA Cleanup and Concentration Kit (Fisher BioReagents, Pittsburgh, PA, USA) according to the manufacturer's instructions.

\subsection{RNA Sequencing and Mapping}

For cDNA library preparation, a NEB Next Ultra II Directional RNA Library Prep Kit for Illumina (New England Biolabs, Ipswich, MA, USA) protocol was used. Singleend sequencing (read length of 60 nucleotides) was carried out with an Illumina HiSeq 2500 platform (Illumina, San Diego, CA, USA) at the Joint KFU-Riken Laboratory, Kazan Federal University (Kazan, Russia). The quality of reads was examined using FastQC v0.11.7 software and reads were filtered using the BBTools package version 37.9 [30]. Clean reads (median read length 60) were mapped to the $P$. sativum v1a reference genome [31] using STAR 2.5.4b software [32] and quantified with featureCounts v2.0 from the Subread package [33].

\subsection{Differential Expression, GO, and KEGG Enrichment Analysis}

For the identification of DEGs, we used DESeq2 software version 1.28.1 [34] with the Wald test (FDR-corrected $p$-value $<0.01, \mid \log 2$ fold change $\mid>1$, results are shown in Table S1). To estimate the functions of the most up- and downregulated DEGs, the NCBI-Blastx algorithm [35] was used; the results are shown in Table S2 (5 BLAST hits for each gene are given). GO enrichment analysis was performed for significant DEGs in each comparison using the topGO package [36] with Fisher's exact test and a GO annotation file provided with reference to the P. sativum v1a genome (significantly enriched GO terms are shown in Table S3, lists of genes from each significantly enriched GO term for each comparison are shown in Table S4). A graphical comparison of the studied samples was made with DESeq2 functionality and the pheatmap package [37]. Venn diagrams of DEGs were constructed using the VennDiagram package [38]. Graphs of significantly enriched GO categories were produced using ggplot2 v3.3.5 [39]. KEGG annotation was carried out using eggNOG-mapper v2.1.6 [40] assigning KEGG Orthology (KO) IDs to each gene. Enrichment analysis of KEGG pathways was performed using clusterProfiler package v3.16.1 [41] (significantly enriched KEGG pathways for each comparison are shown in Table S5).

\section{Results}

\subsection{Laser Microdissection and RNA Sequencing}

In order to study transcriptomic changes during the differentiation of infected cells, we obtained samples of infected plant cells from three histological zones of 11-day-old nodules of pea wild-type line SGE using LMPC (Figure 1, Table 1). Cut material of three biological replicates was used for RNA isolation, library preparation, and sequencing. Summary statistics of the generated RNA-Seq datasets are given in Table 2.

Table 2. Statistics for the sample sequencing and mapping against the reference genome of P. sativum v1a.

\begin{tabular}{cccc}
\hline Tissue Sample & Biological Replicate & Raw Reads & Filtered Reads \\
\hline \multirow{2}{*}{ Early II } & 1 & $22,003,587$ & $21,953,422$ \\
& 2 & $30,443,307$ & $30,376,438$ \\
& 3 & $34,177,880$ & $34,120,254$ \\
\hline \multirow{2}{*}{ Late II } & 1 & $26,368,470$ & $26,309,716$ \\
& 2 & $20,855,263$ & $20,826,237$ \\
8 & 3 & $23,261,468$ & $23,225,423$ \\
\hline \multirow{2}{*}{ III } & 1 & $23,401,941$ & $23,345,915$ \\
& 2 & $25,659,354$ & $25,618,921$ \\
\hline
\end{tabular}



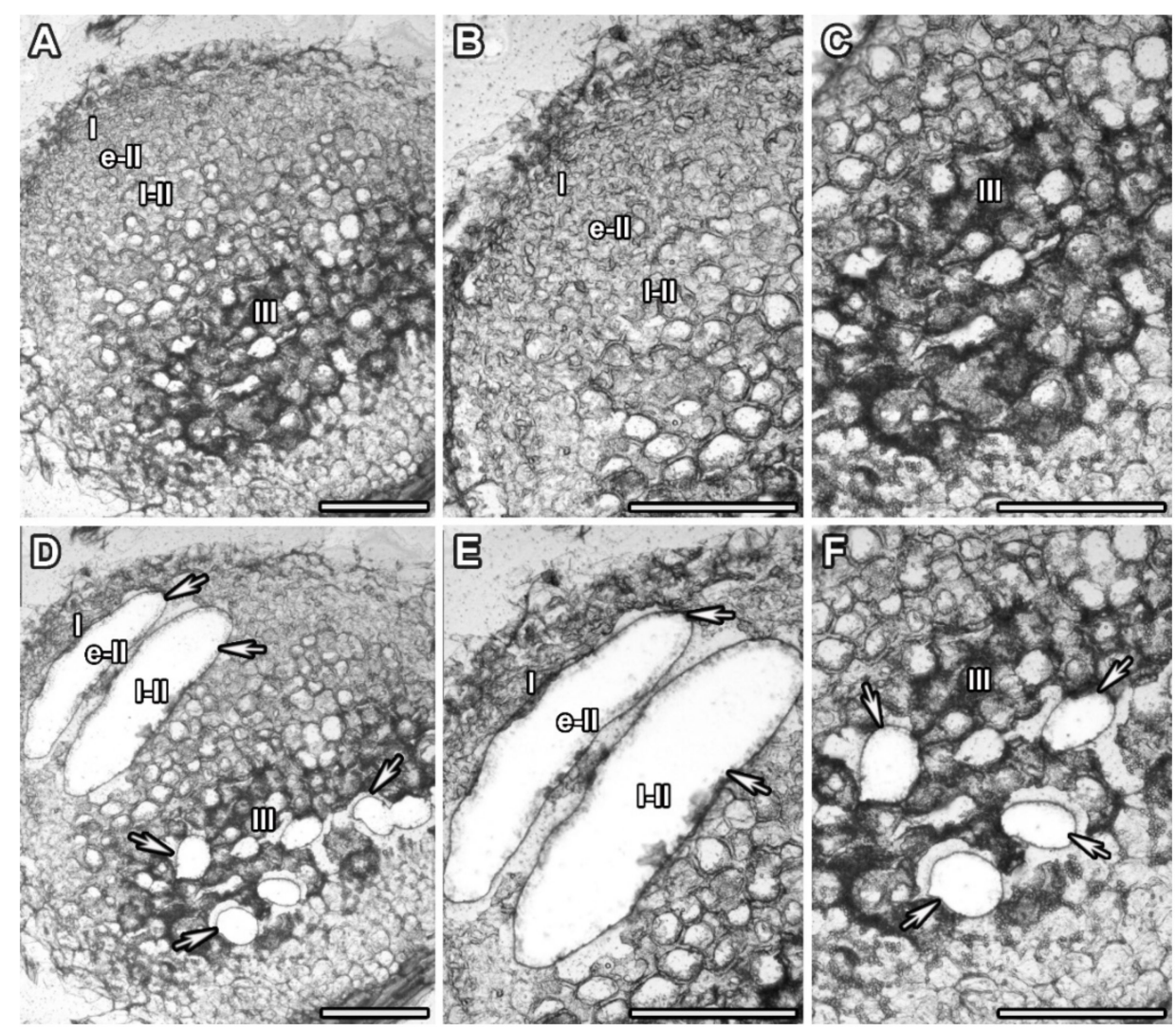

Figure 1. Laser microdissection of histological zones in the 11-day-old symbiotic nodule of the garden pea (Pisum sativum L.) wild-type line SGE. (A), histological organization of the nodule; (B,E), early and late infection zone before (B) and after (E) catapulting; $(\mathbf{C}, \mathbf{F})$, cells of the nitrogen fixation zone before (C) and after (F) catapulting; (D), general view of the nodule after catapulting of target tissues. I, meristem; e-II, early infection zone; 1-II, late infection zone; III, nitrogen fixation zone; arrows indicate cut areas. Scale bars are $150 \mu \mathrm{m}$.

Comparison using principal component analysis revealed a good separation of the studied cell samples with biological replicates grouping together (Figure 2A). Hierarchical clustering using sample-to-sample distances also showed distinct grouping of biological replicates within samples; early and late infection zones were more similar to each other and the nitrogen fixation zone was closer to the late infection zone (Figure 2B).

\subsection{Analysis of Differentially Expressed Genes}

To identify DEGs in all studied samples, three pairwise comparisons were carried out (Figure 3, Table S1): late infection zone against early infection zone (1-II vs. e-II), nitrogen fixation zone against late infection zone (III vs. 1-II), and nitrogen fixation zone against early infection zone (III vs. e-II). Out of 44,756 genes annotated in the P. sativum v1a genome, a total of 3848 genes were identified as upregulated (Figure 3) with the threshold of log2fold change value of 1:899 genes in 1-II vs. e-II, 2296 genes for III vs. 1-II, and 3360 upregulated genes in III vs. e-II comparisons. Some of these genes were unique to each comparison, while some were found in several comparisons: 217 genes were unique for l-II vs. e-II, 271 for III vs. 1-II, and 977 in III vs. e-II. A total of 324 genes were upregulated in all comparisons made, 358 were common for both l-II vs. e-II and III vs. e-II. Furthermore, 1701 common genes were found between III vs. e-II and l-II vs. III contrasts. However, no genes were shared between 1-II vs. e-II and III vs. 1-II. 


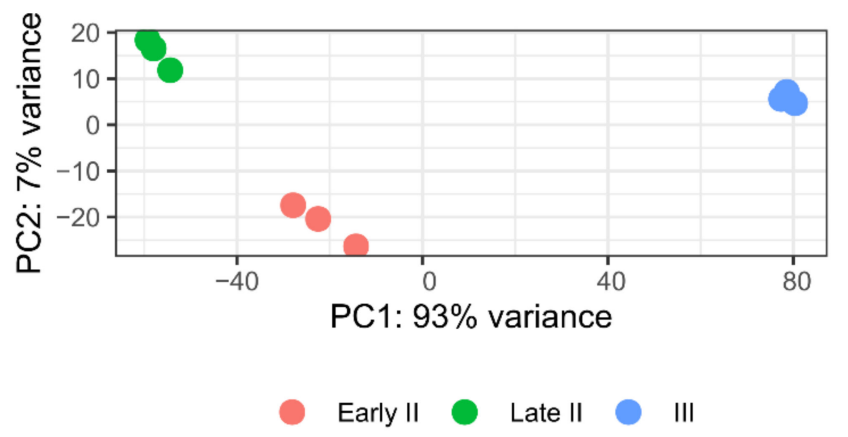

(A)

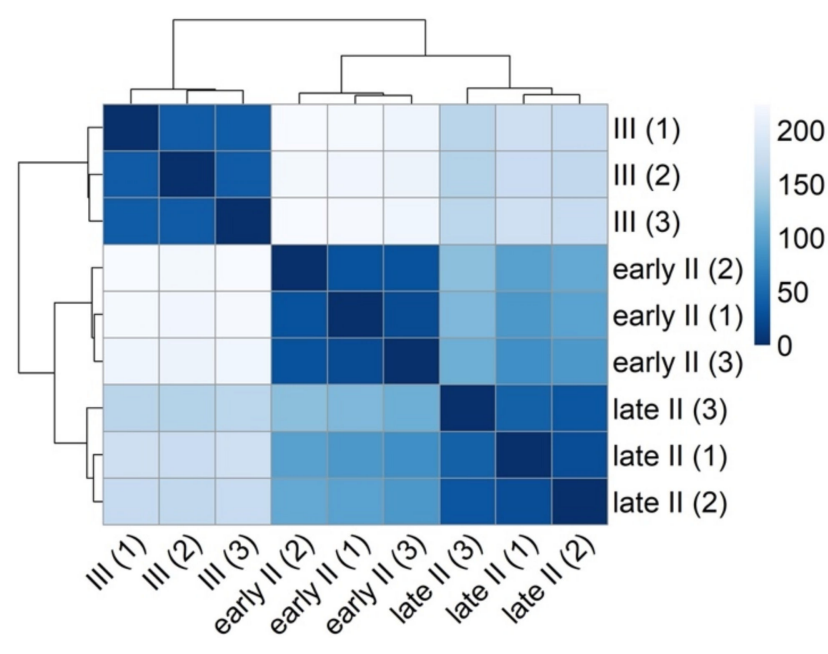

(B)

Figure 2. Comparison of samples from P. sativum nodules. (A) Principal component analysis; (B) Heatmap of the sample-tosample distances. II, infection zone; III, nitrogen fixation zone; Arabic numbers represent biological replicates.

\section{Up-regulated genes}

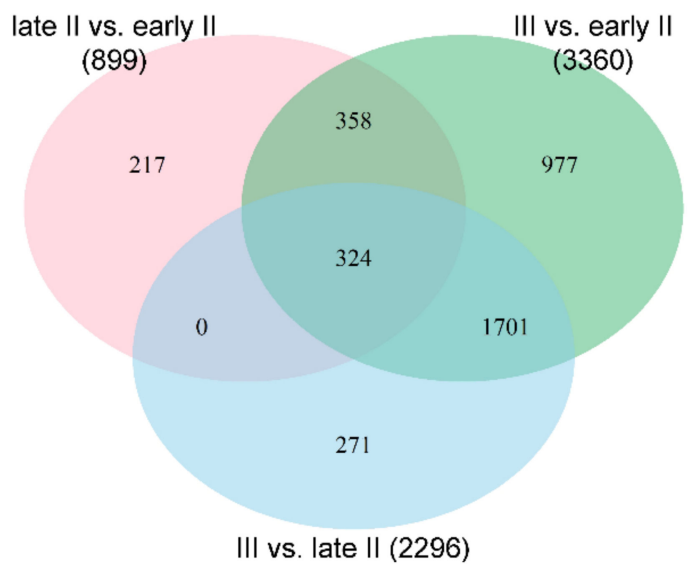

\section{Down-regulated genes}

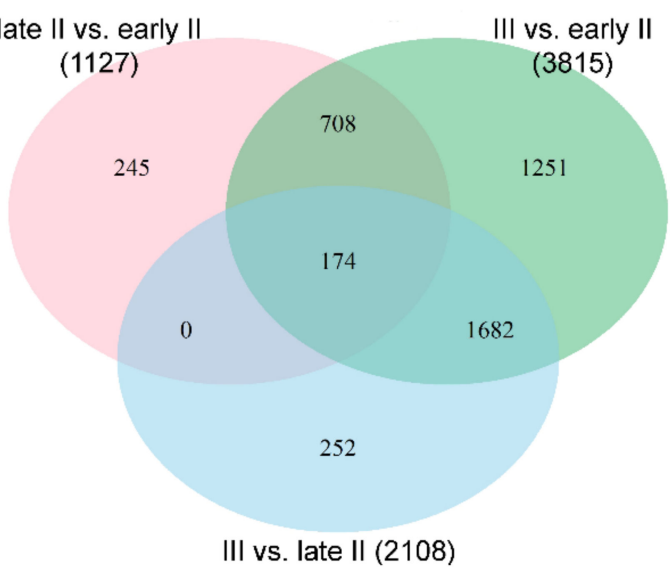

Figure 3. Number of significant differentially expressed genes in comparisons between the studied samples. Sample comparisons are color coded. II, infection zone; III, nitrogen fixation zone. FDR of Wald test $<0.01$.

Downregulation (with the threshold of log2fold change value of -1) was identified in 4312 genes (Figure 3), of which 1127 were in 1-II vs. e-II, 2108 in III vs. 1-II, and 3815 in III vs. e-II. Genes were distributed between comparisons as follows: 174 genes were found in all comparisons, 1682 were identified between III vs. e-II and III vs. 1-II. In addition, no common genes were found between 1-II vs. e-II and III vs. 1-II. A total of 708 genes were downregulated in both the l-II vs. e-II and III vs. e-II comparisons.

We used gene annotation provided with the reference genome and Blastx search to estimate the function of the top 50 most up- and downregulated genes (Table S2). In the l-II vs. e-II comparison, most upregulated genes encoded various nodule cysteine-rich (NCR)- and nodule glycine-rich (NGR)-like peptides, enzymes-like proteases and acidic endochitinases, albumin-1-like protein, leghemoglobin, and MtN21/EamA-like transporterlike. Among the top downregulated genes in this comparison were genes for lateral organ boundaries (LOB) domain-containing proteins, knotted1-like homeobox (KNOX) family regulators, leucine-rich repeat (LRR) ERECTA family proteins, transcription factors from the basic helix-loop-helix (bHLH) family, enzymes of glutamate metabolism (glutamate dehydrogenase, glutamine synthetase), proteins related to root meristem maintenance (root 
meristem growth factor (RGF)8-like, RGF9-like, MtPLETHORA (MtPLT2)-like), calmodulinbinding proteins, pathogen-related genes (PsPR1 and PsPR2), and genes coding various cytochrome enzymes.

In III vs. II-late comparison, several hits for NCRs and NGRs were most upregulated, as well as genes related to the nitrogen transport compounds (cytosolic purine $5^{\prime}$ nucleotidase, asparagine synthetase), leghemoglobin, genes associated with nitrate transport (high-affinity nitrate transporters 2.4-like, glutamine dumper GDU6), polygalacturonase QUARTET (QRT3)-like, NIN-like proteins (NLP) 8/9 hits, CUP-SHAPED COTYLEDON 3 (CUC3/NAC), nodule lectin (PsNlec-1), and calmodulin-binding protein-related gene. The most downregulated transcripts in the same contrast were related to the centromere protein S, MCM1/AGAMOUS/DEFICIENS/SRF(MADS)-box transcription factor AGAMOUS-like (AGL12), 3-epi-6-deoxocathasterone 23-monooxygenase, glucan endo-1,3-beta-glucosidase, sucrose transporter SUCROSE FACILITATOR 1 (SUF1), ethylene-responsive transcription factor, putative cyclin A3-1, histone H2B.3-like, transcription initiation factor TFIID subunit 15-like, and several pentatricopeptide repeat-containing proteins.

Unsurprisingly, the most upregulated genes in the III vs. e-II comparison were genes encoding leghemoglobin and various NCR-like proteins, as well as many unidentified transcripts. The most downregulated were transcripts identified as serine/threonine kinase, centromere protein S/transcription initiation IID, WUSCHEL-related homeobox (WOX5)like, cyclins, cell cycle-regulated microtubule-associated targeting protein for Xklp2 (TPX2), related to calmodulin binding, and glutaredoxin family protein hit.

\subsection{Gene Ontology and KEGG Enrichment Analysis}

To investigate the biological process, molecular function, and cellular component association of DEGs in all comparisons, we performed GO enrichment analysis for significant DEGs in each comparison and significantly enriched GO terms were reported (Figures 4-6, Table S3). Additionally, we provided lists of genes from each significantly enriched GO term for each comparison (Table S4). When compared to the GO annotation file provided with the reference genome, assigned GO terms were found for 2862 upregulated genes of all 3848 reported upregulated DEGs (657 of 899 in 1-II vs. e-II, 2491 of 3360 in III vs. e-II, and 1693 of 2296 in III vs. 1-II). For downregulated genes, 3443 genes had assigned GO annotations of the reported 4312 DEGs (868 of 1127 in 1-II vs. e-II, 3005 of 3815 in III vs. e-II, and 1704 of 2108 in III vs. 1-II). Several GO categories were unique for each comparison while others were represented in multiple comparisons simultaneously. Upregulated biological process terms (Figure 4) comprised biosynthetic processes as well as mitochondrial fission, response to freezing, and photoreactive repair, and were found only in the l-II vs. e-II comparison. The molecular function terms (Figure 5) were substrate binding, activity of phosphorelay sensor kinases (genes from this category were annotated as involved in cytokinin and ethylene signaling), and activity related to heme oxidation. Downregulated genes in biological process terms (Figure 4) were related to immune system, catabolism of polysaccharides, organization of microtubule cytoskeleton, response to organic substances, assembly of spliceosomal complex, termination of DNA-templated transcription, and cell cycle checkpoint GO categories. Molecular function terms (Figure 5) were enzymatic activities (oxidoreductase, histone-lysine methyltransferase, DNA N-glycosylase, and 6-phosphofructokinase activities), and activity of microtubular motor. 


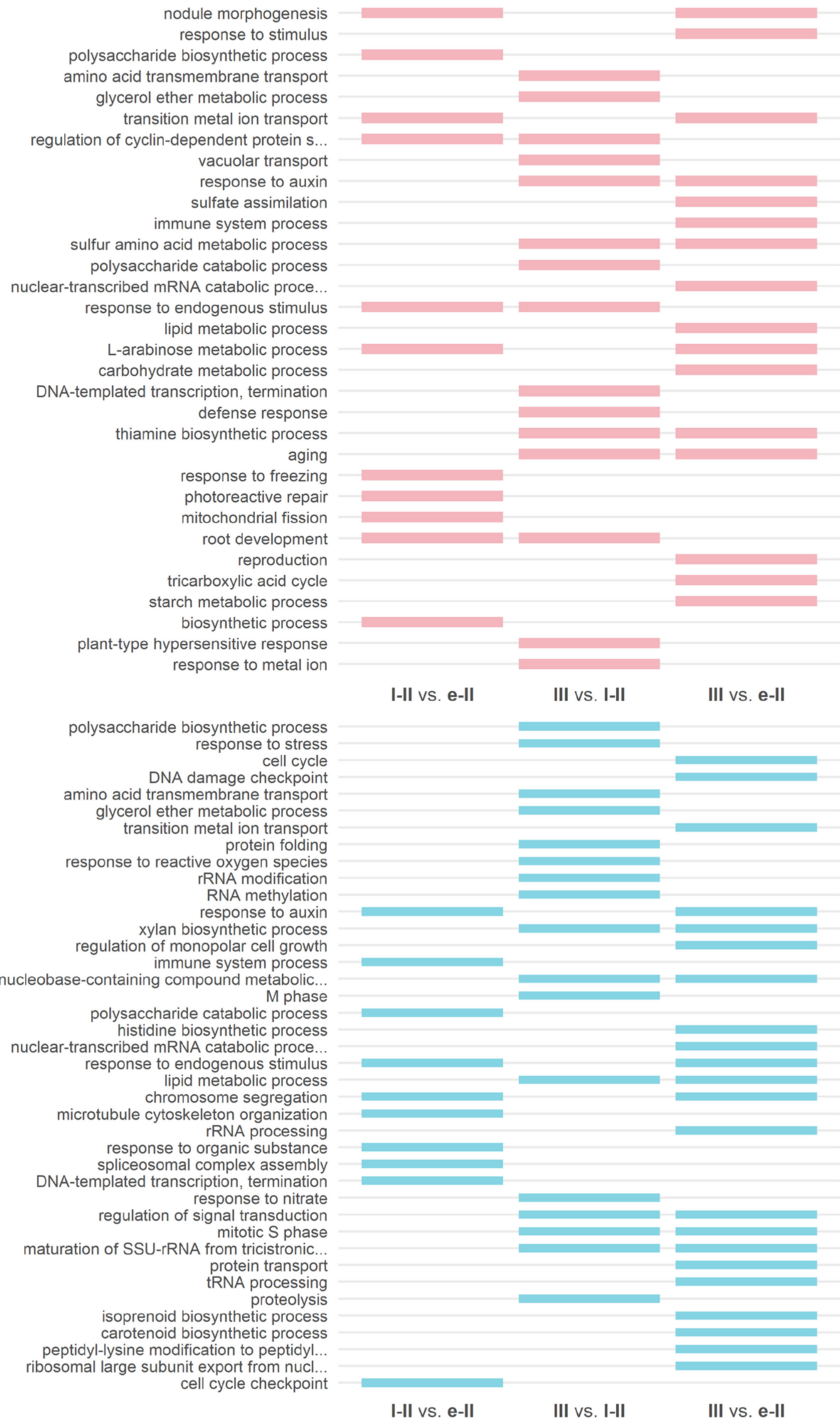

Figure 4. Biological process GO enrichment of the differentially expressed genes in comparisons of the studied samples. Downregulated genes in blue, upregulated genes in red. The tiles show the significantly enriched GO terms of samples from each histological zone compared to others. 1-II, late infection zone; e-II, early infection zone; III, nitrogen fixation zone. The graph is based on data presented in Tables S3 and S4. Fisher's test with $p$-value $<0.01$. 


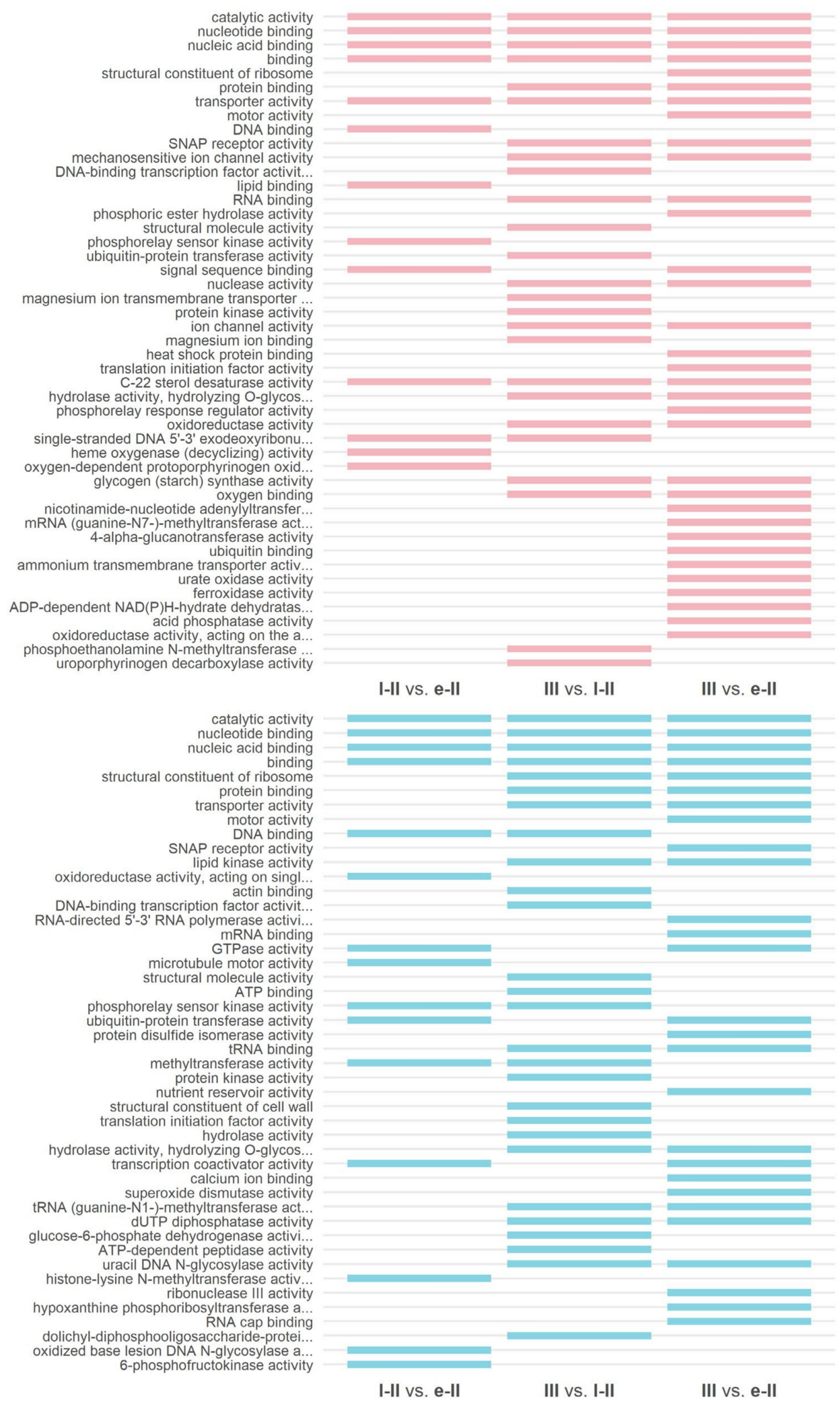

Figure 5. Molecular function GO enrichment of the differentially expressed genes in comparisons of the studied samples. Downregulated genes in blue, upregulated genes in red. The tiles show the significantly enriched GO terms of samples from each histological zone compared to others. 1-II, late infection zone; e-II, early infection zone; III, nitrogen fixation zone. The graph is based on data presented in Tables S3 and S4. Fisher's test with $p$-value $<0.01$. 


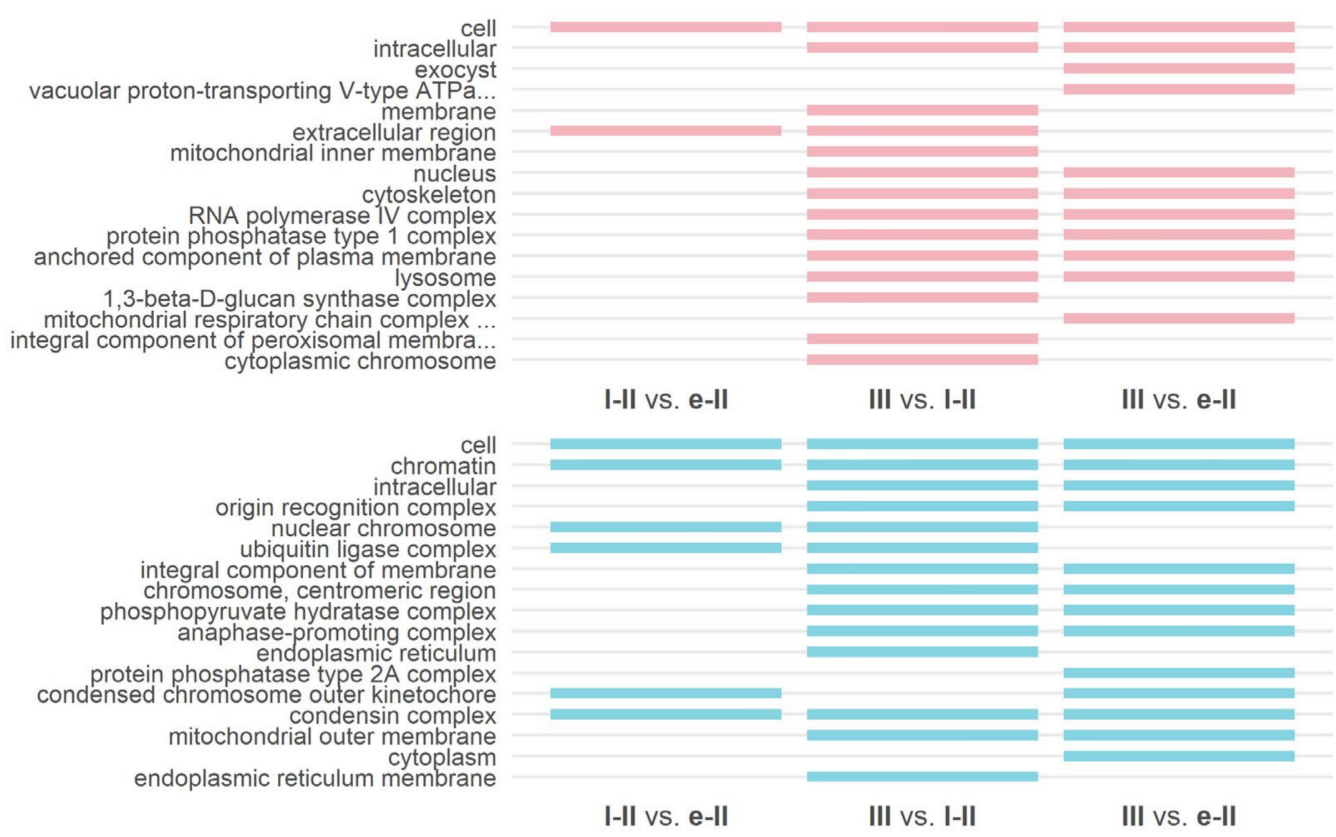

Figure 6. Cellular component GO enrichment of the differentially expressed genes in comparisons of the studied samples. Downregulated genes in blue, upregulated genes in red. The tiles show the significantly enriched GO terms of samples from each histological zone compared to others. 1-II, late infection zone; e-II, early infection zone; III, nitrogen fixation zone. The graph is based on data presented in Tables S3 and S4. Fisher's test with $p$-value $<0.01$.

In III vs. 1-II, unique biological process categories (Figure 4) for upregulated genes were related to such processes as transmembrane and vacuolar transport, polysaccharides catabolism, termination of transcription, and defense reactions. Molecular function categories (Figure 5) were activities of DNA-binding transcription factors, kinases and ubiquitin transferases, transport and binding of $\mathrm{Mg}^{2+}$ ions, as well as uroporphyrinogen decarboxylase activity. For cellular component terms (Figure 6), components of membranes, peroxisome, and 1,3-beta-D-glucan synthase complex were identified. For downregulated genes, the GO biological process categories (Figure 4) were polysaccharide biosynthetic process, response to stress, amino acid transmembrane transport, glycerol ether metabolic process, folding of proteins, response to reactive oxygen species, modification of rRNA and RNA methylation, M phase, response to nitrate, and proteolysis. Significantly enriched molecular function categories (Figure 5) were actin binding, activity of DNA-binding transcription factors, structural molecule activity, binding of ATP, protein kinase activity, structural constituent of cell wall, activity of translation initiation factor, and activity of enzymes (hydrolases, G-6-P dehydrogenases, ATP-dependent peptidases, dolichyl-diphosphooligosaccharide-protein glycotransferases). Endoplasmic reticulum and endoplasmic reticulum membrane were enriched for cellular component GO categories (Figure 6).

Unique categories in III vs. e-II for upregulated genes in biological process terms (Figure 4) were related to various metabolic processes (sulfate assimilation, metabolism of lipids and carbohydrates, and tricarboxylic acid cycle), degradation of nuclear mRNA, response to stimulus and immune response, and reproduction. For molecular function (Figure 5), structural components of ribosome and initiation of translation, motor activity, heat shock protein and ubiquitin binding, activity of phosphorelay response regulators (authentic response regulators (ARR)s involved in cytokinin signaling), and various enzymatic activities: phosphoric ester hydrolytic, NAD-, mRNA methyl-, and glucanotransferring, oxidative, as well as activity of ammonium transmembrane transport were identified. For cellular component (Figure 6), exocyst, V-type ATPase, and respiratory chain complex of mitochondria were identified. For downregulated genes, significantly enriched biological process categories (Figure 4) included cell cycle, DNA damage checkpoint, transport of 
transition metal ions, regulation of monopolar cell growth, biosynthetic processes (histidine, isoprenoid, and carotenoid biosynthesis), mRNA catabolism, rRNA and tRNA processing, protein transport, peptidyl-hypusine synthesis, and ribosomal large subunit export from nucleus. For molecular function (Figure 5), motor activity, synaptosomal-associated protein (SNAP) receptor (SNARE) activity, RNA polymerase activity, mRNA binding, protein disulfide isomerase activity, nutrient reservoir activity, calcium ion binding, superoxide dismutase activity, ribonuclease III activity, hypoxanthine phosphoribosyltransferase activity, and RNA cap binding were identified. For cellular component terms, cytoplasm and protein phosphatase type 2A complex were enriched (Figure 6).

In order to investigate metabolic changes associated with differentiation of infected nodule cells, we performed KEGG pathway enrichment analysis on differentially expressed genes for each comparison (Table S5). Assigned KO IDs were found for 1741 upregulated genes (364 for 1-II vs. e-II, 1028 for III vs. 1-II, 1528 for III vs. e-II) and for 2314 downregulated genes (502 for 1-II vs. e-II, 1336 for III vs. 1-II, 2095 for III vs. e-II). For upregulated DEGs, those significantly enriched included 16 KEGG pathways for 1-II vs. e-II, 31 for III vs. 1-II, and 33 for III vs. e-II; for downregulated genes, there were seven enriched pathways in the 1-II vs. e-II comparison, 24 in III vs. 1-II, and 33 in III vs. e-II. Several pathways were found enriched for up- and downregulated genes in the same comparison: "Starch and sucrose metabolism", "MAPK signaling pathway-plant", "Phenylpropanoid biosynthesis", and "Plant hormone signal transduction" for l-II vs. e-II; "Alanine, aspartate and glutamate metabolism", "Biosynthesis of amino acids", "Glutathione metabolism", "MAPK signaling pathway-plant", "Plant hormone signal transduction", and "Plant-pathogen interaction" for III vs. 1-II; "Biosynthesis of amino acids", "Biosynthesis of cofactors", "Fatty acid biosynthesis", "Glycine, serine and threonine metabolism", "MAPK signaling pathwayplant", "Phenylpropanoid biosynthesis", "Plant hormone signal transduction", "Plantpathogen interaction", and "Ubiquitin-mediated proteolysis" for III vs. e-II.

\section{Discussion}

Comparison of DEGs between various nodule histological zones in P. sativum showed notable changes in transcriptomic profiles during the differentiation of infected cells (Figure 3). The most prominent expression changes were associated with cells from the nitrogen fixation zone, which differed from cells of both early and late infection zones in the number of DEGs (especially from the early infection zone), whereas the contrast between early and late infection zones showed fewer DEGs. However, several DEGs were changed in all comparisons made, indicating specific regulation of gene expression at all stages of infected cell differentiation. Recent analysis of transcriptomic datasets of $M$. truncatula nodules and several other legumes, including pea, confirmed that symbiotic nodules are unique organs in terms of specific transcriptomic changes $[25,42,43]$. Our data could indicate that infected cells of the nitrogen fixation zone in P. sativum nodules can make a large contribution to the uniqueness of the nodule.

Cells of the late infection zone (l-II vs. e-II) showed increasing expression (Table S2 list 1) of the subtilisin-like protease gene (Psat4g065680). It is reported that genes from this family are involved in the early stages of arbuscule mycorrhiza formation and nodulation with both rhizobia [44] and Frankia [45]. In the latter, these genes were activated in infected cells (before their transition to nitrogen fixation) [46]. It was suggested that subtilisin-like proteases could be involved in cell wall remodeling [47]. In pea nodules, subtilisin-like protease can be involved in active cell wall remodeling accompanying infected cell differentiation [18-21]. Analysis of downregulated genes in this comparison revealed the tendency to suppress nodule morphogenesis-related genes. For instance, we observed the downregulation of genes involved in meristem cell identity, such as the PLETHORA2-like gene (Psat5g287880), which is known to be expressed in root and nodule meristematic cells [48], and one gene resembling G. soja root meristem growth factor 9 (Psat7g050080). The observed downregulation of meristematic genes in the late infection zone was unexpected. Genes characterized as coding LBD16 and LBD18 (Psat3g059000 and Psat3g115560, 
respectively) were downregulated in this comparison. In M. truncatula, LBD16 is activated by cytokinin-induced NIN that leads to the creation of auxin maximum required for nodule formation [49]. Additionally, LBD16 and LBD18 proteins are known to be involved in lateral root development in plants and play a role in the induction and regulation of cell cycle genes [50]. Another link to auxin activity is the downregulation of the PSIAA4 gene [51] (Psat6g102800); it is known that IAA genes are involved in the repression of transcription of the early auxin-responsive genes [52]. Among the 50 most downregulated genes in this comparison was a gene from the KNOX family (Psat0s1648g0080). Previously, it has been shown that in the pea, KNOX3 transcription factor could be involved in the upregulation of cytokinin biosynthesis genes [53], and its expression was high in 2-week-old wild-type nodules, but it was decreased in mutants impaired in infection development that correlated with the cytokinin accumulation patterns [17]. The decrease in expression of KNOX family genes in the infection zone observed in this study may indicate different roles for members of this family. Several genes involved in anti-pathogen defense were found to be downregulated, e.g., ERECTA-related gene (Psat6g022040) and PR1- and PR2-related genes (Psat1g156240 and Psat1g213200, respectfully). ERECTA in Arabidopsis thaliana is known to be related to cell wall-mediated responses to pathogens [54]. PR genes are known to be suppressed in plants during the early steps of nodulation $[55,56]$. However, our data indicated that plants also suppress their defense system during the late stages of nodule development. Indeed, in P. satioum, mutations in the genes PsSym33 and PsSym40 encoding transcriptional factors CYCLOPS and ETHYLENE RESPONSE FACTOR REQUIRED FOR NODULE DIFFERENTIATION (EFD) [10] manifest strong defense reactions [20,57]. It is well known that expansins are involved in cell wall plasticity [58]. At the same time, the role of expansins in nodulation has not been well studied; however, there is some evidence that members of this family are present in the various nodule zones (including the infection zone in P. sativum nodules) [59-61]. Thus, downregulation of the Psat7g152680 gene, which has an expansin-a16/a20-like signature in the late infection zone, where plant cells undergo intensive growth, is not clear, but probably indicates a potential involvement of other members of this family during nodule infection.

In the III vs. 1-II comparison (Table S2 list 2), among the most upregulated genes alongside the genes of NCRs and NGRs, surprisingly, we observed a significant upregulation of the Psat2g033440 gene, characterized as cytosolic purine $5^{\prime}$-nucleotidase. This enzyme is known to be involved in the synthesis of ureides, which are the main transport form of assimilated nitrogen in determinate nodules [62,63]. Nevertheless, upregulation of the asparagine synthetase gene (Psat5g153000) involved in the nitrogen assimilation pathway typical for indeterminate nodules, such as P. sativum and M. truncatula [64], has also been reported. Several genes with signatures of the high-affinity nitrate transporter 2.4-like were also found to be upregulated in this comparison (Psat4g155600, Psat7g149120). In Lotus japonicus, NRT2.4 was characterized as a main nitrate transporter in nodules [65], thus suggesting a similar role in indeterminate nodules and emphasizing that it is specifically activated in the nitrogen fixation zone. The gene Psat3g193960 has the signature for glutamine dumper 6 protein, which in A. thaliana is a plasma membrane transporter for glutamine (and possibly other amino acids) export [66]. It has been proposed that in Vicia faba, indeterminate nodule amino acid transport includes an apoplastic step with infected cells exporting amino acids to the apoplastic compartment $[67,68]$. A similar mechanism is probably present in P. satioum nodules. We also found that the polygalacturonase QRT3-like gene was upregulated (Psat1g066920). Considering the involvement of polygalacturonases in cell wall modification during cell enlargement, it is likely that it acts in a similar manner during the enlargement of infected cells. Noticeable induction of the NIN-like gene (Psat7g208800) has been observed while transcripts of PSNIN have not been detected in the nitrogen fixation zone [69]. However, a different role of NIN genes at the late stages of nodule development has been described [70]. The Psat6g053920 gene, characterized as encoding a member of the CUC3/NAC family of transcriptional factors, was among the most upregulated transcripts in this comparison. Previously, it was shown that a member 
from this family in M. truncatula is involved in senescence suppression [9,71]. It can be assumed that a similar mechanism is possible in 11-day-old P. sativum nodules.

Predictably, in this comparison, among the downregulated genes were genes involved in the transcription initiation (gene Psat5g055240 characterized as centromere protein S/transcription initiation factor IID), cell cycle control (cyclin-A-3-1-like gene Psat5g040080), and histoneH2B.3-like (Psat6g173520) and meristem functioning (gene Psat7g151360 characterized as AGL MADS-box, which in Arabidopsis is involved in root meristem functioning [72]). Previously, in nodules of $M$. truncatula, the expression of genes controlling the cell cycle and histones was not detected in zone III [73]. At the same time, a notable decline in the expression of several genes with pentatricopeptide signature (Psat6g072560, Psat5g033520, Psat6g083600, Psat2g174920, Psat7g088720, Psat6g069280.1) was observed. This is a large family of proteins with various functions, often acting as organelle regulators [74]. Currently, there are no data regarding how these molecules could act during nodule development and cell differentiation. Reported downregulation of the Psat4g097000 gene (characterized as 3-epi-6-deoxocathasterone 23-monooxygenase known to be involved in brassinosteroid biosynthesis in A. thaliana [75]) follows recent studies on the role of brassinosteroids in nodule development and functioning that noted little effect of this phytohormone on the mature nodule in P. sativum [76]. In concert with the PR gene suppression in the late infection zone described above, we noted that expression of the Psat1g006640 gene, characterized as a gene encoding a glucan endo-1,3-beta-glucosidaselike protein, was decreased. In soybean, this enzyme was induced as a part of the defense against pathogens and suppressed after inoculation by rhizobia [77]. Furthermore, we detected a downregulation of the P. sativum SUF1 gene (Psat1g106800). This gene, encoding the sucrose transporter SUF1, was previously reannotated as PsSUT1.2 [78]. Little is known about the role of such transporters in nodule function, despite some reports that members of this family are expressed in M. truncatula nodules [79] and that, in L. japonicus, transcription of a member of the similar clade, SUT4, was high in all tissues in young nodules and decreased in infected tissues in mature nodules [80].

In the III vs. e-II comparison (Table S2 list 3), in concert with reported repression of meristem and cell cycle genes in III zone vs. 1-II zone, the downregulation of cyclin and cell cycle-dependent genes was observed. Furthermore, we noted the suppression of the WOX5-like gene (Psat5g127000). In P. sativum and M. truncatula, the expression of related genes remained significant throughout the infection zone in 12-14-day-old nodules and was limited to several cells in mature nodules [81]. The Psat3g160440 gene, which is characterized as glutaredoxin-like, was also suppressed. Previously it was shown that in $M$. truncatula, the expression of some genes encoding glutaredoxins was specifically activated or suppressed in nodules and was associated with bacteroid differentiation [82]. It is interesting to note that recent studies of glutathione distribution, which is a substrate for this molecule, revealed a high amount of glutathione in symbiosomes in infected cells [83].

Comparison of significantly enriched GO terms showed similar patterns to DEGs with most functional groups belonging to the comparison of the III zone with infection zones (Figures 4-6). In these cells, according to the GO term enrichment, many biosynthetic processes were inhibited, which indicates significant metabolic rearrangements during the differentiation of these cells, while the processes of catabolism and aging were activated. It is worth noting that in P. sativum nodules, the senescence zone is usually formed at later stages of development [84-86]. It is one more indication that activation of cell transition to senescence in symbiotic nodules occurs much earlier than the first visible signs of senescence. Recently, mistargeting of potassium ion channels in infected nodule cells and a drastic decrease of $\mathrm{K}^{+}$during their life span have been described [87]. These observations may indicate that infected cells undergo some type of stress. We analyzed genes from the ion channel activity GO group upregulated in zone III and found that two of them, Psat0s3462g0080 and Psat0s3343g0080, were closely related to the genes for $\mathrm{K}^{+}$channels, MtAKT1 and MtSKOR/GORK, described in the study mentioned above, and the third gene (Psat1g221320) was characterized as AKT2/3. This indicates a similar role of these 
$\mathrm{K}^{+}$channels in P. sativum-infected cells. Furthermore, in downregulated genes, we observed groups related to cell cycle regulation, chromosome organization, and transcription that indicated considerable changes in cells during endoreduplication and differentiation. Expression of genes associated with the organization of tubulin cytoskeleton and motor proteins was already decreased in cells of the late infection zone, while in the cells of the nitrogen fixation zone, we observed a switch in motor proteins, an increase in the vacuolar transport genes, and also a decrease of genes for actin interaction. These data may indicate a connection between cell differentiation and changes in the organization and functioning of the cytoskeleton in plant cells. Indeed, crucial changes in tubulin and actin cytoskeleton rearrangements during nodule development in different legume species have been described $[11,12,88-90]$. The observed "switch" when the same functional groups were enriched with both down- and upregulated genes in the same comparisons was reported for several GO categories and KEGG pathways. This indicated that different genes from the same groups were involved in many processes at different stages of differentiation and that genes from such functional groups may be of interest as potentially specific for a particular stage of cell differentiation.

\section{Conclusions}

Here, the analysis of DEGs in three histological zones of pea nodules was carried out for the first time. Significant differences between the zones were revealed. The greatest alterations of expression were observed during the transition to the nitrogen fixation zone, which emphasizes the special status of this zone, whose infected cells are adapted for a specific function, i.e., accommodating organelle-like symbiosomes. The study of the genes with the most changeable expression revealed genes whose functions are well known in the development of the nodule, and those whose participation in the differentiation of infected cells had not been previously shown. One of these gene families is the pentatricopeptides family, known in plants as organelle regulators. Therefore, the approach used in this study can serve both to identify the number of DEGs at different stages of nodule development, and also to allow us to identify new players in this process. Unfortunately, it is necessary to note that data on differential gene expression in nodules, especially taking into account the tissue-specific expression, are still insufficient. Further research is needed to bridge the gap with transcriptome studies in other legumes, especially M. truncatula.

Supplementary Materials: The following are available online at https:/ / www.mdpi.com/article/10 .3390/agronomy11122504/s1, Table S1: The full list of differentially expressed genes in comparisons of studied histological zones of P. sativum nodule, Table S2: Blastx results for the most differentially expressed genes in all comparisons made, Table S3: Significantly enriched GO terms in comparisons of studied histological zones of P. sativum nodule, Table S4: Genes comprising significantly enriched GO terms in comparisons of studied histological zones of $P$. sativum nodule, Table S5: Significantly enriched KEGG metabolic pathways in all comparisons made.

Author Contributions: Conceptualization, V.E.T.; laser capture microdissection and RNA probe preparation, T.A.S.; RNA-Seq, N.E.G.; transcriptome analysis and visualization, P.G.K.; writingoriginal draft preparation, P.G.K.; writing—review and editing, V.E.T. and Y.V.G.; project administration V.E.T. All authors have read and agreed to the published version of the manuscript.

Funding: This research was funded by the Ministry of Science and Higher Education of the Russian Federation in accordance with agreement № 075152020920 date 16 November 2020 on providing a grant in the form of subsidies from the Federal budget of Russian Federation. The grant was provided for state support for the creation and development of a World class Scientific Center "Agrotechnologies for the Future".

Institutional Review Board Statement: Not applicable.

Informed Consent Statement: Not applicable.

Data Availability Statement: The data presented in this study are openly available at NCBI SRA under the accession number PRJNA773870. 
Acknowledgments: The research was performed using equipment belonging to the Core Centrum "Genomic Technologies, Proteomics and Cell Biology" in All-Russia Research Institute for Agricultural Microbiology. Y.V.G. and N.E.G. are grateful to the Ministry of Science and Higher Education of the Russian Federation for their administrative support within the framework of the government assignment for FRC Kazan Scientific Center of the RAS.

Conflicts of Interest: The authors declare no conflict of interest.

\section{References}

1. Oldroyd, G.E. Speak, friend, and enter: Signalling systems that promote beneficial symbiotic associations in plants. Nat. Rev. Microbiol. 2013, 11, 252-263. [CrossRef] [PubMed]

2. Timmers, A.C.J. The role of the plant cytoskeleton in the interaction between legumes and rhizobia. J. Microsc. 2008, 231, 247-256. [CrossRef] [PubMed]

3. Tsyganova, A.V.; Brewin, N.J.; Tsyganov, V.E. Structure and development of the legume-rhizobial symbiotic interface in infection threads. Cells 2021, 10, 1050. [CrossRef] [PubMed]

4. Guinel, F.C. Getting around the legume nodule: I. The structure of the peripheral zone in four nodule types. Botany 2009, 87, 1117-1138. [CrossRef]

5. Brewin, N.J. Plant cell wall remodelling in the Rhizobium-legume symbiosis. Crit. Rev. Plant Sci. 2004, 23, 293-316. [CrossRef]

6. Tsyganova, A.V.; Kitaeva, A.B.; Tsyganov, V.E. Cell differentiation in nitrogen-fixing nodules hosting symbiosomes. Funct. Plant Biol. 2018, 45, 47-57. [CrossRef]

7. Van de Velde, W.; Guerra, J.C.P.; Keyser, A.D.; De Rycke, R.; Rombauts, S.; Maunoury, N.; Mergaert, P.; Kondorosi, E.; Holsters, M.; Goormachtig, S. Aging in legume symbiosis. A molecular view on nodule senescence in Medicago truncatula. Plant Physiol. 2006, 141, 711-720. [CrossRef]

8. Kondorosi, E.; Kondorosi, A. Endoreduplication and activation of the anaphase-promoting complex during symbiotic cell development. FEBS Lett. 2004, 567, 152-157. [CrossRef]

9. Roy, S.; Liu, W.; Nandety, R.S.; Crook, A.; Mysore, K.S.; Pislariu, C.I.; Frugoli, J.; Dickstein, R.; Udvardi, M.K. Celebrating 20 years of genetic discoveries in legume nodulation and symbiotic nitrogen fixation. Plant Cell 2020, 32, 15-41. [CrossRef]

10. Tsyganov, V.E.; Tsyganova, A.V. Symbiotic regulatory genes controlling nodule development in Pisum sativum L. Plants 2020, 9, 1741. [CrossRef]

11. Kitaeva, A.B.; Demchenko, K.N.; Tikhonovich, I.A.; Timmers, A.C.J.; Tsyganov, V.E. Comparative analysis of the tubulin cytoskeleton organization in nodules of Medicago truncatula and Pisum sativum: Bacterial release and bacteroid positioning correlate with characteristic microtubule rearrangements. New Phytol. 2016, 210, 168-183. [CrossRef]

12. Kitaeva, A.B.; Gorshkov, A.P.; Kirichek, E.A.; Kusakin, P.G.; Tsyganova, A.V.; Tsyganov, V.E. General patterns and species-specific differences in the organization of the tubulin cytoskeleton in indeterminate nodules of three legumes. Cells 2021, 10, 1012. [CrossRef]

13. Maróti, G.; Kondorosi, É. Nitrogen-fixing Rhizobium-legume symbiosis: Are polyploidy and host peptide-governed symbiont differentiation general principles of endosymbiosis? Front. Microbiol. 2014, 5, 326. [CrossRef]

14. Stagnari, F.; Maggio, A.; Galieni, A.; Pisante, M. Multiple benefits of legumes for agriculture sustainability: An overview. Chem. Biol. Technol. Agric. 2017, 4, 2. [CrossRef]

15. Borisov, A.Y.; Danilova, T.N.; Koroleva, T.A.; Kuznetsova, E.V.; Madsen, L.; Mofett, M.; Naumkina, T.S.; Nemankin, T.A.; Ovchinnikova, E.S.; Pavlova, Z.B.; et al. Regulatory genes of garden pea (Pisum sativum L.) controlling the development of nitrogen-fixing nodules and arbuscular mycorrhiza: A review of basic and applied aspects. Appl. Biochem. Microbiol. 2007, 43, 237-243. [CrossRef]

16. Serova, T.A.; Tsyganova, A.V.; Tikhonovich, I.A.; Tsyganov, V.E. Gibberellins inhibit nodule senescence and stimulate nodule meristem bifurcation in pea (Pisum sativum L.). Front. Plant Sci. 2019, 10, 285. [CrossRef]

17. Dolgikh, E.A.; Kusakin, P.G.; Kitaeva, A.B.; Tsyganova, A.V.; Kirienko, A.N.; Leppyanen, I.V.; Dolgikh, A.V.; Ilina, E.L.; Demchenko, K.N.; Tikhonovich, I.A.; et al. Mutational analysis indicates that abnormalities in rhizobial infection and subsequent plant cell and bacteroid differentiation in pea (Pisum sativum) nodules coincide with abnormal cytokinin responses and localization. Ann. Bot. 2020, 125, 905-923. [CrossRef]

18. Sherrier, D.J.; Borisov, A.Y.; Tikhonovich, I.A.; Brewin, N.J. Immunocytological evidence for abnormal symbiosome development in nodules of the pea mutant line Sprint-2Fix ${ }^{-}$(sym31). Protoplasma 1997, 199, 57-68. [CrossRef]

19. Dahiya, P.; Sherrier, D.J.; Kardailsky, I.V.; Borisov, A.Y.; Brewin, N.J. Symbiotic gene Sym31 controls the presence of a lectinlike glycoprotein in the symbiosome compartment of nitrogen-fixing pea nodules. Mol. Plant Microbe Interact. 1998, 11, 915-923. [CrossRef]

20. Ivanova, K.A.; Tsyganova, A.V.; Brewin, N.J.; Tikhonovich, I.A.; Tsyganov, V.E. Induction of host defences by Rhizobium during ineffective nodulation of pea (Pisum sativum L.) carrying symbiotically defective mutations sym40 (PsEFD), sym33 (PsIPD3/PsCYCLOPS) and sym42. Protoplasma 2015, 252, 1505-1517. [CrossRef]

21. Tsyganova, A.V.; Seliverstova, E.V.; Brewin, N.J.; Tsyganov, V.E. Comparative analysis of remodelling of the plant-microbe interface in Pisum sativum and Medicago truncatula symbiotic nodules. Protoplasma 2019, 256, 983-996. [CrossRef] 
22. Roux, B.; Rodde, N.; Jardinaud, M.-F.; Timmers, T.; Sauviac, L.; Cottret, L.; Carrère, S.; Sallet, E.; Courcelle, E.; Moreau, S.; et al. An integrated analysis of plant and bacterial gene expression in symbiotic root nodules using laser-capture microdissection coupled to RNA sequencing. Plant J. 2014, 77, 817-837. [CrossRef]

23. Limpens, E.; Moling, S.; Hooiveld, G.; Pereira, P.A.; Bisseling, T.; Becker, J.D.; Küster, H. Cell- and tissue-specific transcriptome analyses of Medicago truncatula root nodules. PLoS ONE 2013, 8, e64377. [CrossRef]

24. Carrere, S.; Verdier, J.; Gamas, P. MtExpress, a comprehensive and curated rnaseq-based gene expression atlas for the model legume Medicago truncatula. Plant Cell Physiol. 2021, 62, 1494-1500. [CrossRef]

25. Alves-Carvalho, S.; Aubert, G.; Carrère, S.; Cruaud, C.; Brochot, A.-L.; Jacquin, F.; Klein, A.; Martin, C.; Boucherot, K.; Kreplak, J.; et al. Full-length de novo assembly of RNA-seq data in pea (Pisum sativum L.) provides a gene expression atlas and gives insights into root nodulation in this species. Plant J. 2015, 84, 1-19. [CrossRef]

26. Kosterin, O.E.; Rozov, S.M. Mapping of the new mutation blb and the problem of integrity of linkage group I. Pisum Genet. 1993, $25,27-31$.

27. Fåhraeus, G. The infection of clover root hairs by nodule bacteria studied by a simple glass slide technique. J. Gen. Microbiol. 1957, 16, 374-381. [CrossRef]

28. Glenn, A.R.; Poole, P.S.; Hudman, J.F. Succinate uptake by free-living and bacteroid forms of Rhizobium leguminosarum. Microbiology 1980, 119, 267-271. [CrossRef]

29. Serova, T.A.; Tikhonovich, I.A.; Tsyganov, V.E. Analysis of nodule senescence in pea (Pisum sativum L.) using laser microdissection, real-time PCR, and ACC immunolocalization. J. Plant Physiol. 2017, 212, 29-44. [CrossRef]

30. Bushnell, B. BBMap: A Fast, Accurate, Splice-Aware Aligner. Available online: https://jgi.doe.gov/data-and-tools/bbtools/ (accessed on 19 February 2014).

31. Kreplak, J.; Madoui, M.-A.; Cápal, P.; Novák, P.; Labadie, K.; Aubert, G.; Bayer, P.E.; Gali, K.K.; Syme, R.A.; Main, D.; et al. A reference genome for pea provides insight into legume genome evolution. Nat. Genet. 2019, 51, 1411-1422. [CrossRef]

32. Dobin, A.; Davis, C.A.; Schlesinger, F.; Drenkow, J.; Zaleski, C.; Jha, S.; Batut, P.; Chaisson, M.; Gingeras, T.R. STAR: Ultrafast universal RNA-seq aligner. Bioinformatics 2012, 29, 15-21. [CrossRef] [PubMed]

33. Liao, Y.; Smyth, G.K.; Shi, W. featureCounts: An efficient general purpose program for assigning sequence reads to genomic features. Bioinformatics 2014, 30, 923-930. [CrossRef] [PubMed]

34. Love, M.I.; Huber, W.; Anders, S. Moderated estimation of fold change and dispersion for RNA-seq data with DESeq2. Genome Biol. 2014, 15, 550. [CrossRef] [PubMed]

35. Camacho, C.; Coulouris, G.; Avagyan, V.; Ma, N.; Papadopoulos, J.; Bealer, K.; Madden, T.L. BLAST+: Architecture and applications. BMC Bioinform. 2009, 10, 421. [CrossRef]

36. Alexa, A.; Rahnenfuhrer, J. topGO: Enrichment Analysis for Gene Ontology; R Package Version 2.44.0; R Package: Vienna, Austria, 2021.

37. Kolde, R. pheatmap: Pretty Heatmaps; R Package Version 1.0.12; R Package: Vienna, Austria, 2019.

38. Chen, H. VennDiagram: Generate High-Resolution Venn and Euler Plots; R Package Version 1.6.20; R Package: Vienna, Austria, 2018.

39. Wickham, H. ggplot2: Elegant Graphics for Data Analysis; Springer: New York, NY, USA, 2016.

40. Cantalapiedra, C.P.; Hernández-Plaza, A.; Letunic, I.; Bork, P.; Huerta-Cepas, J. eggNOG-mapper v2: Functional annotation, orthology assignments, and domain prediction at the metagenomic scale. Mol. Biol. Evol. 2021. [CrossRef]

41. Yu, G.; Wang, L.G.; Han, Y.; He, Q.Y. clusterProfiler: An R package for comparing biological themes among gene clusters. OMICS J. Integr. Biol. 2012, 16, 284-287. [CrossRef]

42. Mergaert, P.; Kereszt, A.; Kondorosi, E. Gene expression in nitrogen-fixing symbiotic nodule cells in Medicago truncatula and other nodulating plants. Plant Cell 2019, 32, 42-68. [CrossRef]

43. Zhukov, V.A.; Zhernakov, A.I.; Kulaeva, O.A.; Ershov, N.I.; Borisov, A.Y.; Tikhonovich, I.A. De Novo assembly of the pea (Pisum sativum L.) nodule transcriptome. Int. J. Genomics 2015, 2015, 695947. [CrossRef]

44. Takeda, N.; Sato, S.; Asamizu, E.; Tabata, S.; Parniske, M. Apoplastic plant subtilases support arbuscular mycorrhiza development in Lotus japonicus. Plant J. 2009, 58, 766-777. [CrossRef]

45. Laplaze, L.; Ribeiro, A.; Franche, C.; Duhoux, E.; Auguy, F.; Bogusz, D.; Pawlowski, K. Characterization of a Casuarina glauca nodule-specific subtilisin-like protease gene, a homolog of Alnus glutinosa ag12. Mol. Plant Microbe Interact. 2000, 13, 113-117. [CrossRef]

46. Ribeiro, A.; Akkermans, A.D.; van Kammen, A.; Bisseling, T.; Pawlowski, K. A nodule-specific gene encoding a subtilisin-like protease is expressed in early stages of actinorhizal nodule development. Plant Cell 1995, 7, 785-794. [CrossRef]

47. Taylor, A.; Qiu, Y.-L. Evolutionary history of subtilases in land plants and their involvement in symbiotic interactions. Mol. Plant Microbe Interact. 2017, 30, 489-501. [CrossRef]

48. Franssen, H.J.; Xiao, T.T.; Kulikova, O.; Wan, X.; Bisseling, T.; Scheres, B.; Heidstra, R. Root developmental programs shape the Medicago truncatula nodule meristem. Development 2015, 142, 2941-2950. [CrossRef]

49. Schiessl, K.; Lilley, J.L.S.; Lee, T.; Tamvakis, I.; Kohlen, W.; Bailey, P.C.; Thomas, A.; Luptak, J.; Ramakrishnan, K.; Carpenter, M.D.; et al. NODULE INCEPTION recruits the lateral root developmental program for symbiotic nodule organogenesis in Medicago truncatula. Curr. Biol. 2019, 29, 3657-3668. [CrossRef]

50. Lee, H.W.; Cho, C.; Kim, J. Lateral organ boundaries domain16 and 18 act downstream of the AUXIN1 and LIKE-AUXIN3 auxin influx carriers to control lateral root development in Arabidopsis. Plant Physiol. 2015, 168, 1792-1806. [CrossRef] 
51. Ballas, N.; Wong, L.-M.; Theologis, A. Identification of the auxin-responsive element, $A u x R E$, in the primary indoleacetic acid-inducible gene, PS-IAA4/5, of pea (Pisum sativum). J. Mol. Biol. 1993, 233, 580-596. [CrossRef]

52. Parry, G.; Estelle, M. Auxin receptors: A new role for F-box proteins. Curr. Opin. Cell Biol. 2006, 18, 152-156. [CrossRef]

53. Azarakhsh, M.; Kirienko, A.N.; Zhukov, V.A.; Lebedeva, M.A.; Dolgikh, E.A.; Lutova, L.A. KNOTTED1-LIKE HOMEOBOX 3: A new regulator of symbiotic nodule development. J. Exp. Bot. 2015, 66, 7181-7195. [CrossRef]

54. Sánchez-Rodríguez, C.; Estévez, J.M.; Llorente, F.; Hernández-Blanco, C.; Jordá, L.; Pagán, I.; Berrocal, M.; Marco, Y.; Somerville, S.; Molina, A. The ERECTA receptor-like kinase regulates cell wall-mediated resistance to pathogens in Arabidopsis thaliana. Mol. Plant Microbe Interact. 2009, 22, 953-963. [CrossRef]

55. Mithöfer, A. Suppression of plant defence in rhizobia-legume symbiosis. Trends Plant Sci. 2002, 7, 440-444. [CrossRef]

56. Mitra, R.M.; Long, S.R. Plant and bacterial symbiotic mutants define three transcriptionally distinct stages in the development of the Medicago truncatula/Sinorhizobium meliloti symbiosis. Plant Physiol. 2004, 134, 595-604. [CrossRef]

57. Tsyganova, A.V.; Seliverstova, E.V.; Brewin, N.J.; Tsyganov, V.E. Bacterial release is accompanied by ectopic accumulation of cell wall material around the vacuole in nodules of Pisum sativum sym33-3 allele encoding transcription factor PsCYCLOPS / PsIPD3. Protoplasma 2019, 256, 1449-1453. [CrossRef]

58. Cosgrove, D.J. Growth of the plant cell wall. Nat. Rev. Mol. Cell Biol. 2005, 6, 850-861. [CrossRef]

59. Giordano, W.; Hirsch, A.M. The expression of MaEXP1, a Melilotus alba expansin gene, is upregulated during the sweetcloverSinorhizobium meliloti interaction. Mol. Plant Microbe Interact. 2004, 17, 613-622. [CrossRef]

60. Sujkowska, M.; Borucki, W.; Golinowski, W. Localization of expansin-like protein in apoplast of pea (Pisum sativum L.) root nodules during interaction with Rhizobium leguminosarum bv.viciae 248. Acta Soc. Bot. Pol. 2007, 76, 17-26. [CrossRef]

61. Li, X.; Zhao, J.; Tan, Z.; Zeng, R.; Liao, H. GmEXPB2, a cell wall $\beta$-expansin, affects soybean nodulation through modifying root architecture and promoting nodule formation and development. Plant Physiol. 2015, 169, 2640-2653. [CrossRef]

62. Smith, P.M.C.; Atkins, C.A. Purine biosynthesis. Big in cell division, even bigger in nitrogen assimilation. Plant Physiol. 2002, 128, 793-802. [CrossRef]

63. Garneau, M.G.; Tan, Q.; Tegeder, M. Function of pea amino acid permease AAP6 in nodule nitrogen metabolism and export, and plant nutrition. J. Exp. Bot. 2018, 69, 5205-5219. [CrossRef]

64. Udvardi, M.; Poole, P.S. Transport and metabolism in legume-rhizobia symbioses. Annu. Rev. Plant Biol. 2013, 64, 781-805. [CrossRef]

65. Valkov, V.T.; Sol, S.; Rogato, A.; Chiurazzi, M. The functional characterization of LjNRT2.4 indicates a novel, positive role of nitrate for an efficient nodule $\mathrm{N}_{2}$-fixation activity. New Phytol. 2020, 228, 682-696. [CrossRef]

66. Pratelli, R.; Voll, L.M.; Horst, R.J.; Frommer, W.B.; Pilot, G. Stimulation of nonselective amino acid export by glutamine dumper proteins. Plant Physiol. 2009, 152, 762-773. [CrossRef] [PubMed]

67. Peiter, E.; Yan, F.; Schubert, S. Amino acid export from infected cells of Vicia faba root nodules: Evidence for an apoplastic step in the infected zone. Physiol. Plant. 2004, 122, 107-114. [CrossRef]

68. White, J.; Prell, J.; James, E.K.; Poole, P. Nutrient sharing between symbionts. Plant Physiol. 2007, 144, 604-614. [CrossRef] [PubMed]

69. Borisov, A.Y.; Madsen, L.H.; Tsyganov, V.E.; Umehara, Y.; Voroshilova, V.A.; Batagov, A.O.; Sandal, N.; Mortensen, A.; Schauser, L.; Ellis, N.; et al. The Sym35 gene required for root nodule development in pea is an ortholog of Nin from Lotus japonicus. Plant Physiol. 2003, 131, 1009-1017. [CrossRef]

70. Liu, J.; Bisseling, T. Evolution of NIN and NIN-like genes in relation to nodule symbiosis. Genes 2020, 11, 777. [CrossRef]

71. De Zélicourt, A.; Diet, A.; Marion, J.; Laffont, C.; Ariel, F.; Moison, M.; Zahaf, O.; Crespi, M.; Gruber, V.; Frugier, F. Dual involvement of a Medicago truncatula NAC transcription factor in root abiotic stress response and symbiotic nodule senescence. Plant J. 2012, 70, 220-230. [CrossRef]

72. Burgeff, C.; Liljegren, S.J.; Tapia-López, R.; Yanofsky, M.F.; Alvarez-Buylla, E.R. MADS-box gene expression in lateral primordia, meristems and differentiated tissues of Arabidopsis thaliana roots. Planta 2002, 214, 365-372. [CrossRef]

73. Vinardell, J.M.; Fedorova, E.; Cebolla, A.; Kevei, Z.; Horvath, G.; Kelemen, Z.; Tarayre, S.; Roudier, F.; Mergaert, P.; Kondorosi, A.; et al. Endoreduplication mediated by the anaphase-promoting complex activator CCS52A is required for symbiotic cell differentiation in Medicago truncatula nodules. Plant Cell 2003, 15, 2093-2105. [CrossRef]

74. Barkan, A.; Small, I. Pentatricopeptide repeat proteins in plants. Annu. Rev. Plant Biol. 2014, 65, 415-442. [CrossRef]

75. Ohnishi, T.; Szatmari, A.-M.; Watanabe, B.; Fujita, S.; Bancos, S.; Koncz, C.; Lafos, M.; Shibata, K.; Yokota, T.; Sakata, K.; et al. C-23 hydroxylation by Arabidopsis CYP90C1 and CYP90D1 reveals a novel shortcut in brassinosteroid biosynthesis. Plant Cell 2006, 18, 3275-3288. [CrossRef]

76. McGuiness, P.N.; Reid, J.B.; Foo, E. Brassinosteroids play multiple roles in nodulation of pea via interactions with ethylene and auxin. Planta 2020, 252, 70. [CrossRef]

77. Khatoon, A.; Rehman, S.; Salavati, A.; Komatsu, S. A comparative proteomics analysis in roots of soybean to compatible symbiotic bacteria under flooding stress. Amino Acids 2012, 43, 2513-2525. [CrossRef]

78. Doidy, J.; Vidal, U.; Lemoine, R. Sugar transporters in Fabaceae, featuring SUT MST and SWEET families of the model plant Medicago truncatula and the agricultural crop Pisum sativum. PLoS ONE 2019, 14, e0223173. [CrossRef] 
79. Kryvoruchko, I.S.; Sinharoy, S.; Torres-Jerez, I.; Sosso, D.; Pislariu, C.I.; Guan, D.; Murray, J.; Benedito, V.A.; Frommer, W.B.; Udvardi, M.K. MtSWEET11, a nodule-specific sucrose transporter of Medicago truncatula. Plant Physiol. 2016, 171, 554-565. [CrossRef]

80. Flemetakis, E.; Dimou, M.; Cotzur, D.; Efrose, R.C.; Aivalakis, G.; Colebatch, G.; Udvardi, M.; Katinakis, P. A sucrose transporter, LjSUT4, is up-regulated during Lotus japonicus nodule development. J. Exp. Bot. 2003, 54, 1789-1791. [CrossRef]

81. Osipova, M.A.; Mortier, V.; Demchenko, K.N.; Tsyganov, V.E.; Tikhonovich, I.A.; Lutova, L.A.; Dolgikh, E.A.; Goormachtig, S. WUSCHEL-RELATED HOMEOBOX5 gene expression and interaction of CLE peptides with components of the systemic control add two pieces to the puzzle of autoregulation of nodulation. Plant Physiol. 2012, 158, 1329-1341. [CrossRef]

82. Alloing, G.; Mandon, K.; Boncompagni, E.; Montrichard, F.; Frendo, P. Involvement of glutaredoxin and thioredoxin systems in the nitrogen-fixing symbiosis between legumes and rhizobia. Antioxidants 2018, 7, 182. [CrossRef]

83. Ivanova, K.A.; Chernova, E.N.; Kulaeva, O.A.; Tsyganova, A.V.; Kusakin, P.G.; Russkikh, I.V.; Tikhonovich, I.A.; Tsyganov, V.E. The regulation of pea (Pisum sativum L.) symbiotic nodule infection and defense responses by glutathione, homoglutathione, and their ratio. Front. Plant Sci. 2021. submitted.

84. Kijne, J.W. The fine structure of pea root nodules. 2. Senescence and disintegration of the bacteroid tissue. Physiological Plant Pathology 1975, 7, 17-21. [CrossRef]

85. Kneen, B.E.; LaRue, T.A.; Hirsch, A.M.; Smith, C.A.; Weeden, N.F. sym 13-A gene conditioning ineffective nodulation in Pisum sativum. Plant Physiol. 1990, 94, 899-905. [CrossRef]

86. Serova, T.A.; Tsyganova, A.V.; Tsyganov, V.E. Early nodule senescence is activated in symbiotic mutants of pea (Pisum sativum L.) forming ineffective nodules blocked at different nodule developmental stages. Protoplasma 2018, 255, 1443-1459. [CrossRef]

87. Fedorova, E.E.; Coba de la Peña, T.; Lara-Dampier, V.; Trifonova, N.A.; Kulikova, O.; Pueyo, J.J.; Lucas, M.M. Potassium content diminishes in infected cells of Medicago truncatula nodules due to the mislocation of channels MtAKT1 and MtSKOR/GORK J. Exp. Bot. 2021, 72, 1336-1348. [CrossRef]

88. Fedorova, E.E.; de Felipe, M.R.; Pueyo, J.J.; Lucas, M.M. Conformation of cytoskeletal elements during the division of infected Lupinus albus L. nodule cells. J. Exp. Bot. 2007, 58, 2225-2236. [CrossRef]

89. Gavrin, A.; Jansen, V.; Ivanov, S.; Bisseling, T.; Fedorova, E. ARP2/3-mediated actin nucleation associated with symbiosome membrane is essential for the development of symbiosomes in infected cells of Medicago truncatula root nodules. Mol. Plant Microbe Interact. 2015, 28, 605-614. [CrossRef]

90. Zhang, X.; Han, L.; Wang, Q.; Zhang, C.; Yu, Y.; Tian, J.; Kong, Z. The host actin cytoskeleton channels rhizobia release and facilitates symbiosome accommodation during nodulation in Medicago truncatula. New Phytol. 2019, 221, 1049-1059. [CrossRef] 